\title{
CLASSIFICAÇÃO DE SISTEMAS METEOROLÓGICOS E COMPARAÇÃO DA PRECIPITAÇÃO ESTIMADA PELO RADAR E MEDIDA PELA REDE TELEMÉTRICA NA BACIA HIDROGRÁFICA DO ALTO TIETÊ
}

\author{
FABRÍCIO DANIEL DOS SANTOS SILVA ${ }^{1,2}$, AUGUSTO JOSÉ PEREIRA FILHO ${ }^{2}$, \\ RICARDO HALLAK ${ }^{2}$
}

\author{
${ }^{1}$ Coordenação de Desenvolvimento e Pesquisa, \\ Instituto Nacional de Meteorologia (CDP/INMET), Brasília-DF. \\ ${ }^{2}$ Departamento de Ciências Atmosféricas, Instituto de Astronomia, \\ Geofísica e Ciências Atmosféricas, \\ Universidade de São Paulo (IAG/USP), Cidade Universitária, São Paulo, SP. \\ silva@model.iag.usp.br, apereira@model.iag.usp.br, \\ hallak@model.iag.usp.br
}

Recebido Agosto 2008 - Aceito Agosto 2009

RESUMO

Foram analisadas características da precipitação estimada a partir de 145.194 campos de refletividade, de um total de 827 dias entre 1998 e 2003, obtidos do Radar Meteorológico de São Paulo (RSP). Os eventos foram classificados de acordo com intensidades de precipitação; em Convectivos (EC) e Estratiformes (EE). Quanto à morfologia, cinco tipos de sistemas foram identificados; Convecção Isolada (CI), Brisa Marítima (BM), Linhas de Instabilidade (LI), Bandas Dispersas (BD) e Frentes Frias (FF). Eventos convectivos dominam na primavera e verão e estratiformes no outono e inverno. A CI e a BM tiveram maiores picos de atuação entre outubro e março enquanto as FF de abril a setembro. $\mathrm{BD}$ atuam durante todo o ano e as LI só não foram observadas nos meses de junho e julho. Uma comparação pontual entre a precipitação medida pela telemetria e estimada com o radar foi realizada e, mostrou haver, na maioria dos casos, um viés positivo do RSP, para acumulações de 10, 30 e 60 minutos. Com o objetivo de integrar as estimativas de precipitação do radar com as medidas da rede telemétrica, por meio de uma análise objetiva estatística, foram obtidas dos campos de precipitação do radar as estruturas das correlações espaciais em função da distância para acumulações de chuva de $15,30,60$ e 120 minutos para os cinco tipos de sistemas precipitantes que foram caracterizados. As curvas das correlações espaciais médias de todos os eventos de precipitação de cada sistema foram ajustadas por funções polinomiais de sexta ordem. Os resultados indicam diferenças significativas na estrutura espacial das correlações entre os sistemas precipitantes.

Palavras-chave: sistemas precipitantes, radar meteorológico, precipitação acumulada, correlações espaciais.

\begin{abstract}
CLASSIFICATION OF METEOROLOGICAL SYSTEMS AND COMPARISON OF RADAR ESTIMATED PRECIPITATION TO THE MEASURED BY TELEMETRIC NETWORK IN THE HIGH TIETÊ WATERSHED

Estimated precipitation characteristics arising from 145.194 reflectivity fields, from 827 days, during the period from 1998 to 2003, obtained at the Weather Radar of São Paulo, were analysed. The events were classified according to the intensity of precipitation in Convectives and Stratiforms. Five types of morphologic systems were identified: Isolated Convection (CI), Maritime Breeze (BM), Squall Lines (LI), Dispersed Bands (BD), and Cold Fronts (FF). Convection events dominate in spring and summer and Stratiforms in the Autumn and Winter. CI and BM have occurred more frequently between October and March, while the cold fronts from April to September. Dispersed Bands occurred throughout the year, and the lines of instability did not occur only on June and July. A comparison between the telemetric measured precipitation and the Radar estimated one has been done, and a positive bias, of
\end{abstract}


the Radar accumulations for 10,30 and 60 minutes, was shown on the majority of cases. To integrate the precipitation estimations from the Radar to the telemetric network measurements, by means of an objective statistical analysis, the structures of spatial correlation, for rain accumulation during 15, 30, 60 and 120 minutes for the five types of characterized systems, was obtained from the Radar precipitation fields. The average spatial correlation curves of all the precipitation events of each system were fitted to a sixth order polynomial function. The results indicate significant differences in the spatial structures of the correlation among the precipitation systems.

Keywords: precipitation systems, weather radar, accumulated precipitation, spatial correlation.

\section{INTRODUÇÃO}

A Região Metropolitana de São Paulo (RMSP) se insere na bacia hidrográfica do Alto Tietê (BAT), com uma área de $5.985 \mathrm{~km}^{2}$, abrangendo 39 municípios. A bacia ocupa apenas $2,7 \%$ do território paulista e concentra quase $50 \%$ da população do Estado. Em 2001, a população da RMSP era de aproximadamente 17,5 milhões de pessoas, $60 \%$ desta no município de São Paulo. Em virtude das recorrentes enchentes na RMSP, estabeleceu-se em 1976 uma rede telemétrica com pluviômetros e limnígrafos (Barros e Braga, 1992). Embora tal rede tenha uma grande utilidade na obtenção de dados para análise e previsão de precipitações, esta abrange pequenas regiões comparadas à própria RMSP. Assim, para melhorar o monitoramento da região foi instalado em 1998 um radar meteorológico em Ponte Nova (Pisani, 1995), o que permitiu uma melhoria na resolução espaço-temporal das estimativas da chuva e previsão de enchentes (Pereira Filho e Barros, 1998). O radar meteorológico monitora a precipitação em um raio de alcance superior a $120 \mathrm{~km}$, com resolução espaço-temporal equivalente a uma rede telemétrica com cerca de 1 pluviômetro a cada $2 \mathrm{~km}$ x $2 \mathrm{~km}$. Este monitoramento é de fundamental importância para a RMSP, que sofre com freqüentes inundações do Rio Tietê. Em geral, as enchentes ocorrem entre setembro a março (Pereira Filho e Silva, 2005).

A maioria dos eventos de enchentes está associada a chuvas induzidas pela ilha de calor e a circulação da brisa marítima (Pereira Filho 1999). Há ainda os eventos devido à orografia (Blanco e Massambani, 1997), sistemas convectivos de mesoescala (Silva Dias 1989), sistemas frontais (Satyamurty et al, 1990) e a Zona de Convergência do Atlântico Sul - ZCAS (Rocha e Gandú 1996). Fenômenos de grande escala tais como episódios de El Niño e La Niña (Gan e Rao, 1991; Marengo et al, 1998) também modulam os regimes de precipitação na região.

O radar meteorológico é sensível a vários fatores físicos que podem resultar em estimativas errôneas por parte deste sistema. Austin (1987) concluiu que para cada tipo de situação sinótica, deve haver uma equação de transformação da refletividade medida $(Z)$ em taxa de precipitação $(R)$. Mesmo sendo um sistema passível de erros, gera informações de alta resolução espaço - temporal da precipitação que é de extrema importância para a previsão de tempo em curtíssimo prazo (até 3 horas). Vários estudos foram realizados para comparar a precipitação estimada por radar e redes de superfície, sob diferentes tipos de situação sinótica e revelaram haver diferentes desvios e viéses que dependem, muitas vezes, do tipo de precipitação convectiva ou estratiforme (Zawadzki 1973; Smith et al, 1996). Assim, nota-se a importância de analisar, classificar e caracterizar a precipitação estimada pelo RSP, e comparar com a precipitação medida pela rede telemétrica para períodos mais extensos do que realizado em estudo anterior (Pereira Filho e Nakayama 2001).

Este estudo teve como primeiro objetivo caracterizar e classificar os principais sistemas meteorológicos, que atuam na área de cobertura do RSP, em função da intensidade da precipitação e de fatores que discriminam os diferentes tipos de sistemas meteorológicos. Além disto, comparou-se a precipitação estimada pelo radar com as medidas da rede telemétrica instalada na BAT, para analisar o viés do radar em relação às observações.

Apesar dos erros das estimativas do radar e das medidas telemétricas, estas podem ser combinadas para diminuição de tais erros (Pereira Filho e Crawford 1995), por meio de técnicas de análises objetivas estatísticas (ANOBES). Visando esta aplicação, como segundo objetivo, neste trabalho foi obtida a estrutura espacial da correlação do erro dos campos de precipitação do RSP, para cinco tipos de sistemas precipitantes, classificados segundo sua morfologia: convecção isolada (CI), brisa marítima (BM), linhas de instabilidade (LI), bandas dispersas (BD) e frentes frias (FF). Estas correlações foram obtidas para intervalos de acumulação de 15, 30, 60 e 120 minutos, para possibilitar posteriormente a integração das estimativas do radar com as medidas de chuva da rede telemétrica, por meio de uma técnica de ANOBES. Aqui são discutidas, apenas, as propriedades estatísticas das estruturas destas correlações espaciais. 


\section{DADOS E METODOLOGIA}

\section{a) Radar}

Para este estudo, foram utilizados dados do RSP instalado na barragem de Ponte Nova, na cabeceira do rio Tietê. Este radar pertence ao Departamento de Águas e Energia Elétrica (DAEE) do Estado de São Paulo.

Um conjunto de dados deste radar foi disponibilizado pelo DAEE, para o período 1998 a 2003, consistindo de estimativas de precipitação a partir de campos de refletividade no nível de altura constante de $3 \mathrm{~km}$ (CAPPI- Constant Altitude Plan Position Indicator), com resolução espacial de $4 \mathrm{~km}^{2}$ e resolução temporal de 5 minutos. O CAPPI padrão do DAEE está em $3 \mathrm{~km}$ por este se situar geralmente abaixo da banda brilhante e logo acima das montanhas, fatores que geram erros significativos na estimativa de chuva. O primeiro superestima a chuva devido ao derretimento dos cristais de gelo próximo a isoterma de $0^{\circ} \mathrm{C}$, e o segundo, gera ecos de terreno, prejudicando a estimativa de chuva em áreas de topografia elevadas (Pereira Filho et al, 1990). As refletividades foram convertidas para taxas de precipitação $(\mathrm{mm} / \mathrm{h})$, que permitiram discriminar a precipitação entre convectiva e estratiforme, assim como também identificar cinco tipos de sistemas precipitantes que atuam durante todo o ano, dentro da área de cobertura do RSP. A relação refletividadetaxa de precipitação empregada operada pelo DAEE para este radar é a de Marshall e Palmer (1948): $Z=200 \mathrm{R}^{1,6}$, onde $Z$ é a refletividade das gotas em determinado volume de ar iluminado pelo radar, $\mathrm{R}$ é a taxa de precipitação em $\mathrm{mmh}^{-1}$.
Neste estudo, sistemas com taxas de precipitação menores que $20 \mathrm{~mm} / \mathrm{h}$ foram classificados como estratiformes e, convectivos, acima de $20 \mathrm{~mm} / \mathrm{h}$. Este limiar é arbitrário, outros poderiam ser usados. A precipitação convectiva apresenta alto gradiente horizontal de taxas de precipitação, taxas de precipitação elevadas e correntes ascendentes intensas. Por outro lado, baixas taxas de precipitação apresentam baixo gradiente horizontal de precipitação e correntes ascendentes fracas caracterizando a região de precipitação estratiforme. Este limiar foi escolhido analisando basicamente os gradientes de precipitação dos campos das taxas de precipitação (mm/ h), sendo escolhido o limiar de $20 \mathrm{~mm} / \mathrm{h}$ tendo em vista a climatologia dos sistemas precipitantes no leste do Estado de São Paulo (Chandrasekar e Zafar, 2004). De acordo com este limiar, os eventos foram classificados, de acordo com a intensidade de precipitação, em Eventos Convectivos (EC) e Eventos Estratiformes (EE).

Para classificação dos sistemas foram usados 145.194 campos de precipitação estimada em um total de 827 dias, entre janeiro de 1998 e dezembro de 2003. Os demais dias não apresentaram dados por ausência de convecção ou não foram usados por falhas de dados. Cada evento foi analisado, subjetivamente, por meio da animação dos campos de taxa de precipitação de cada um dos eventos de chuva a fim de identificar e caracterizar os sistemas meteorológicos. De acordo com as imagens, foram montados arquivos com informações sobre horários de início e dissipação dos sistemas, sentidos de deslocamento e de direção de propagação dos sistemas, de modo a diferenciar os sistemas precipitantes entre si. Em conformidade

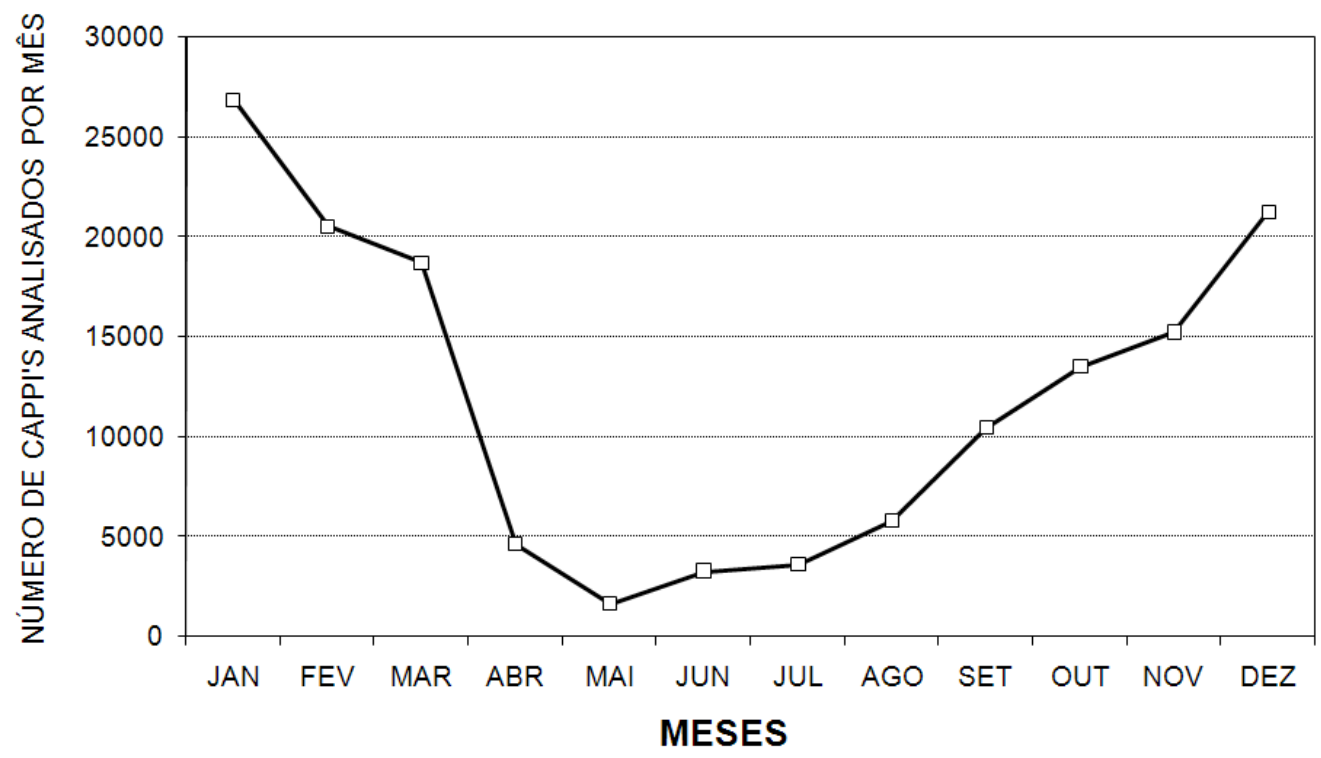

Figura 1 - Número total de CAPPI's disponíveis para análise, para cada mês. 
com o ciclo climatológico anual de precipitação na região, a maior quantidade de mapas disponíveis ocorreu nos meses de verão e o menor no inverno (Figura 1).

\section{b) Rede Telemétrica}

ABAT conta com uma rede telemétrica (Barros e Braga, 1992) para medições de precipitação em 27 pontos espacialmente distribuídos (Figura 2), com resultados de acumulações a cada 10 minutos. Para cada posto, foi comparada a precipitação medida com a estimada pelo radar na posição do respectivo posto, dividindo-se o total estimado pelo radar, pelo total medido no posto para verificar o viés das estimativas do radar em relação às medidas observadas nos postos. Esta comparação foi possível devido à alta resolução espacial dos dados do radar. Para cada acumulação de chuva em 10 minutos, foram obtidos valores acumulados de duas varreduras sucessivas do radar, contendo, cada varredura, campos de taxa de precipitação a cada 5 minutos.

Verificou-se que, para cada posto, o radar geralmente superestimava a precipitação em quantidades relativamente homogêneas, e apesar de haver outros métodos que conduziriam a possíveis erros menores na estimativa final do viés radar telemetria, como o método das isoietas e dos polígonos de Thiessen (Chow et al 1998, Stellman et al 2001), tais verificações motivaram obter um viés médio entre radar e telemetria pela média dos vieses das comparações para cada posto, apesar deste método ignorar as variações geográficas da precipitação, sendo mais aconselhável aplicá-lo em regiões onde isso possa ser feito sem incorrer em grandes erros, como áreas planas com variação gradual e suave do gradiente pluviométrico e com cobertura de postos de medição bastante densa.

Neste estudo, um viés médio maior (menor) do que 1 , indica que o radar superestimou (subestimou) a precipitação. Estimou-se também o coeficiente de correlação de Pearson (Legates e McCabe, 1999) para 10, 30 e 60 minutos de acumulações. O coeficiente de correlação indica a marcha temporal das acumulações derivadas do radar, contra os respectivos pluviômetros. Para tanto, foram usados resultados de 92 dias entre os anos de 1999 e 2000. Tais dias foram os melhores quanto a combinação de horários entre telemetria e radar. Estes resultados são mostrados em gráficos do tipo Box e Whiskers (Wilks, 2006; Evans e Doswell, 2001).

\section{c) Correlações espaciais}

Diferentemente da comparação radar-telemetria, as correlações espaciais do erro do radar foram calculadas a partir dos dados dos campos das taxas de precipitação acumulada para intervalos de 15, 30, 60 e 120 minutos. As correlações espaciais foram determinadas para cada um dos cinco tipos de sistemas identificados: CI, BM, LI, BD e FF. Para tanto, utilizou-se cerca de $30 \%$ dos totais de CAPPI's de cada um dos cinco tipos de sistemas analisados.

A maior vantagem do uso dos dados de radar meteorológico para estimar estas correlações é a alta resolução espaço-temporal dos mesmos. O número total de pontos usados para determinar as correlações da amostra é uma função do número de pares, em que há ao menos um deles com registro de precipitação mensurável. A correlação espacial é função da distância entre os pixels de $2 \mathrm{~km} \times 2 \mathrm{~km}$ para os diferentes intervalos de acumulação citados, e é determinada da média de todas as estimativas de correlação para uma dada distância. Este procedimento extrai a componente isotrópica da correlação espacial. Uma função polinomial é ajustada às médias. A função ajustada deve decrescer monotonicamente com a distância (Pereira Filho et al., 1998). O cálculo destas correlações é de fundamental importância para aplicação de um sistema de ANOBES, pois falhas em considerar o impacto destes erros afetam adversamente os erros da interpolação (Pereira Filho et al, 1998).

A correlação do erro dos campos do radar pode ser estimada por (Pereira Filho at al, 1998):

$$
\rho_{k l}=\frac{\left\langle\left(P_{r}^{k}-P_{t}^{k}\right)\left(P_{r}^{l}-P_{t}^{l}\right)\right\rangle}{\sqrt{\left\langle\left(P_{r}^{k}-P_{t}^{k}\right)^{2}\right\rangle\left\langle\left(P_{r}^{l}-P_{t}^{l}\right)^{2}\right\rangle}}
$$

onde $\langle c\rangle=\int^{\infty} c^{*} p(c) d c$ é um operador, e p(c) = função densidade de probabiliidade de c, $P_{r}^{k(l)}=$ precipitação acumulada pelo radar $(\mathrm{mm})$ no local k (l). Desde que a acumulação verdadeira $P_{t}^{k(l)}$ é desconhecida, $\rho_{\mathrm{kl}}$ é estimada no sentido climatológico (Creutin e Obled 1982) substituindo-se Pt pela média de longas séries de precipitação.

\section{RESULTADOS E DISCUSSÕES}

\section{a) Características e descrição dos sistemas precipitantes observados}

A CI geralmente se forma à tarde sem orientação aparente e pode estar, ou não, associada a algum sistema de grande escala; surge e se dissipa, geralmente, próximo ao local de formação. São células convectivas ordinárias sem deslocamento aparente ou de deslocamento muito lento, e sem região preferencial para formação, sobre o continente. Eventos de CI ocorrem preferencialmente entre 13:30 HL e 18:30 HL, de acordo com o ciclo do aquecimento diurno. Estas células ocorrem em sua grande maioria no interior do continente, seu deslocamento, quando observado, é de oeste para leste na maior parte das 
vezes. Podem dar origem, na fase de decaimento, a áreas de precipitação estratiformes mais extensas do que as células na fase madura de desenvolvimento. A Figura 3 mostra casos típicos de núcleos de CI no período da tarde de um dia de verão, onde se podem observar as características acima descritas.

A BM pode dar origem a sistemas precipitantes convectivos e estratiformes. Os eventos convectivos induzidos pela BM se deslocam para oeste na forma de CI, com características morfológicas semelhantes a CI. Em geral, desenvolvem-se entre 14:30 HL e 19:00 HL e tendem a formar linhas de células convectivas ao longo da costa, as quais são favorecidas pela Serra do Mar. Este tipo de sistema alcança a RMSP, onde normalmente produz precipitação convectiva intensa. Em alguns casos, a BM dá origem a pequenas bandas ou áreas de precipitação estratiforme, com pequeno tempo de vida. Na Figura 4, é possível observar o deslocamento de núcleos convectivos alinhados em direção ao interior do continente, associada à frente de BM.

As LI apresentam em sua dianteira células convectivas intensas com área de precipitação estratiforme na sua retaguarda, deslocando-se rapidamente, em torno de 10 a 12 ms-1. Surgem geralmente da fusão de ecos convectivos isolados ou podem estar associados a outros sistemas, em geral à dianteira ou retaguarda de FF. As LI foram observadas em todos os horários, com predominância entre 15:00 HL e $17 \mathrm{HL}$, com ciclo de vida entre 4 a 12 horas. Foram observados deslocamentos de LI para todas as direções, mas preferencialmente de noroeste para sudeste, perpendiculares ou paralelas ao movimento de sistemas frontais. A Figura 5a mostra o desenvolvimento e propagação de uma linha de instabilidade, situada no quadrante noroeste, de orientação norte-sul, com rápido deslocamento para leste na retaguarda de um sistema frontal. Já a Figura $5 \mathrm{~b}$ apresenta outra linha de instabilidade independente, de orientação sudoeste-nordeste, se deslocando rapidamente no sentido noroeste-sudeste.

As BD não apresentam organização espacial e, geralmente, estão associadas a um sistema de grande escala, tais como frentes estacionárias. Em geral, elas se deslocam de noroeste para sudeste e com chuva estratiforme e convecção embebida nestas. O período de vida destes sistemas pode chegar a até 5 dias, de acordo com os dados de radar. As BD convectivas de maior longevidade estão, em geral, associadas aos episódios de ZCAS. A Figura 6 mostra um caso típico da descrição acima, associado a umas ZCAS ocorrida entre 01 e 08 de janeiro de 2000 (Climanálise, 2000).

As FF apresentam faixas de precipitação de largura variável com orientação noroeste-sudeste, convectivas ou estratiformes, e deslocamento de sudoeste para leste/nordeste. A duração destes sistemas na área de cobertura do radar varia de algumas horas a mais de 5 dias (estacionárias). A média de deslocamento das FF pela área de cobertura do radar meteorológico de SP foi de cerca de 18 horas. Elas atuam em todos os meses do ano, porém são mais convectivas no verão (Figura 7a) do que no inverno (Figura 7b), quando se deslocam com maior velocidade e extensão de chuva estratiforme. Em alguns casos, no verão, estas zonas baroclínicas se tornam

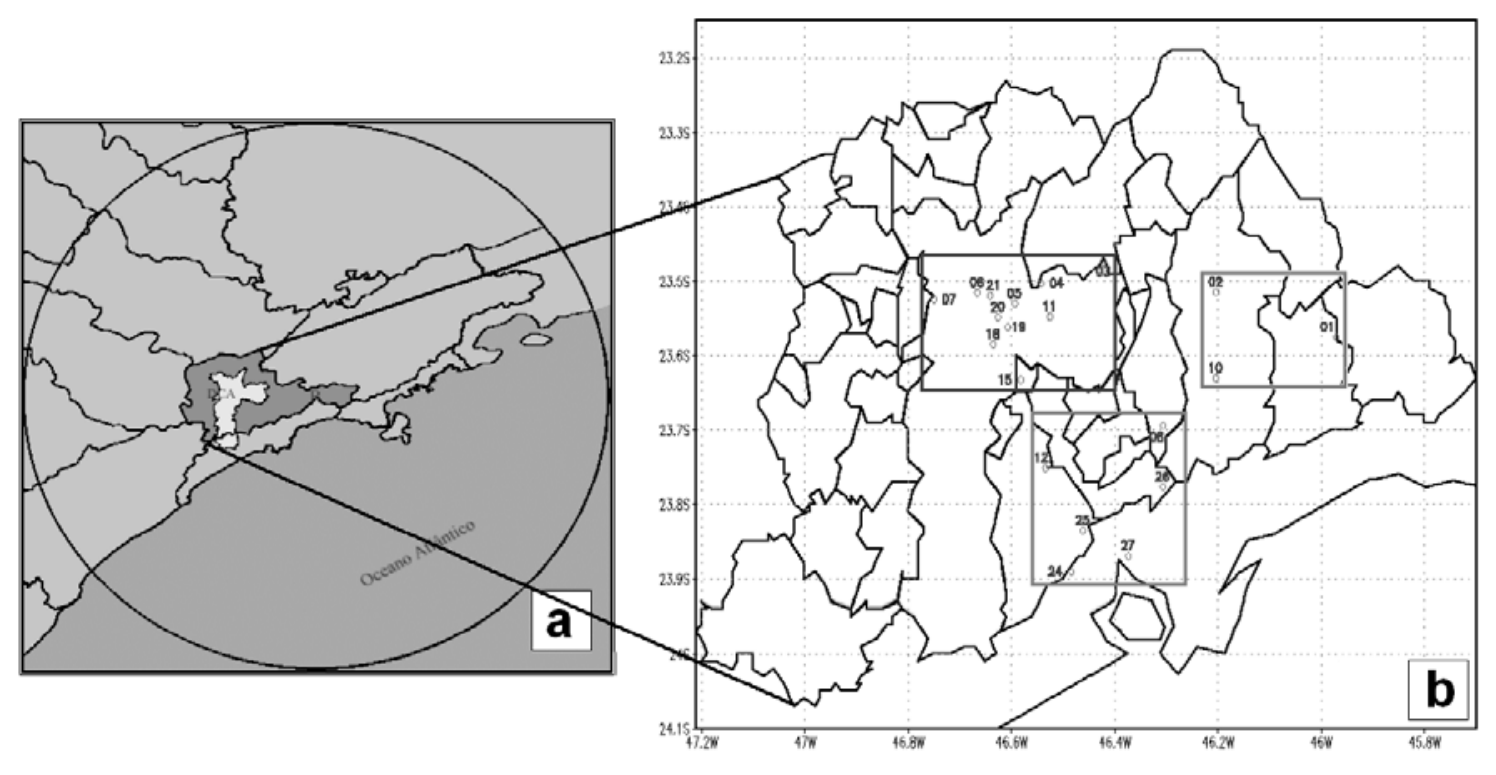

Figura 2 - (a) Área de cobertura do radar meteorológico de São Paulo (Raio de $240 \mathrm{~km}$ ) com destaques para a BAT e a RMSP, e (b) polígonos enquadrando a rede telemétrica da RMSP. 

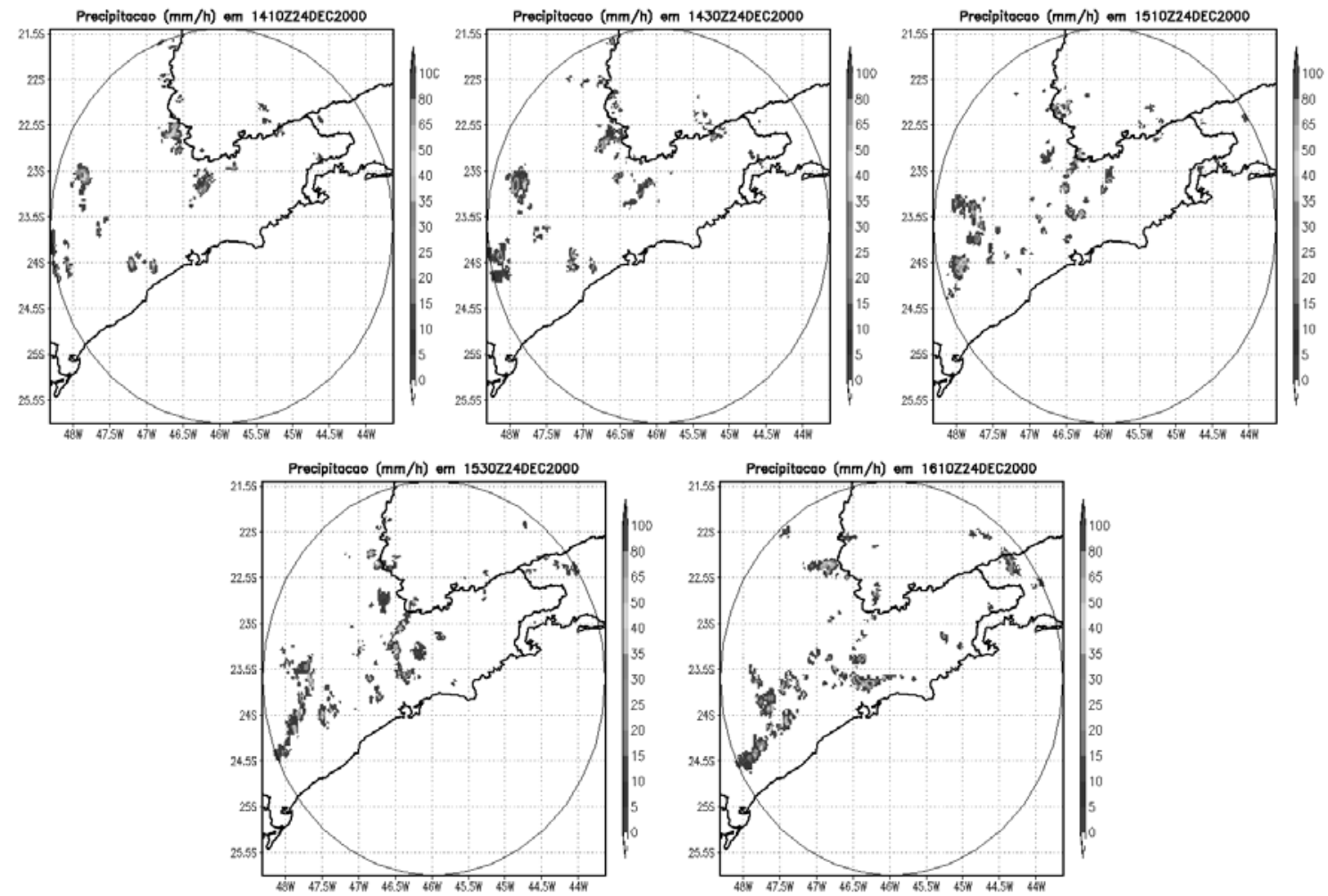

Figura 3 - Campos de taxa de precipitação obtidos com o radar meteorológico de São Paulo, evidenciando atuação de núcleos de CI. Horários (UTC) e datas indicados. Escala de tons de cinza indica a intensidade de precipitação $\left(\mathrm{mm} \mathrm{h}^{-1}\right)$.
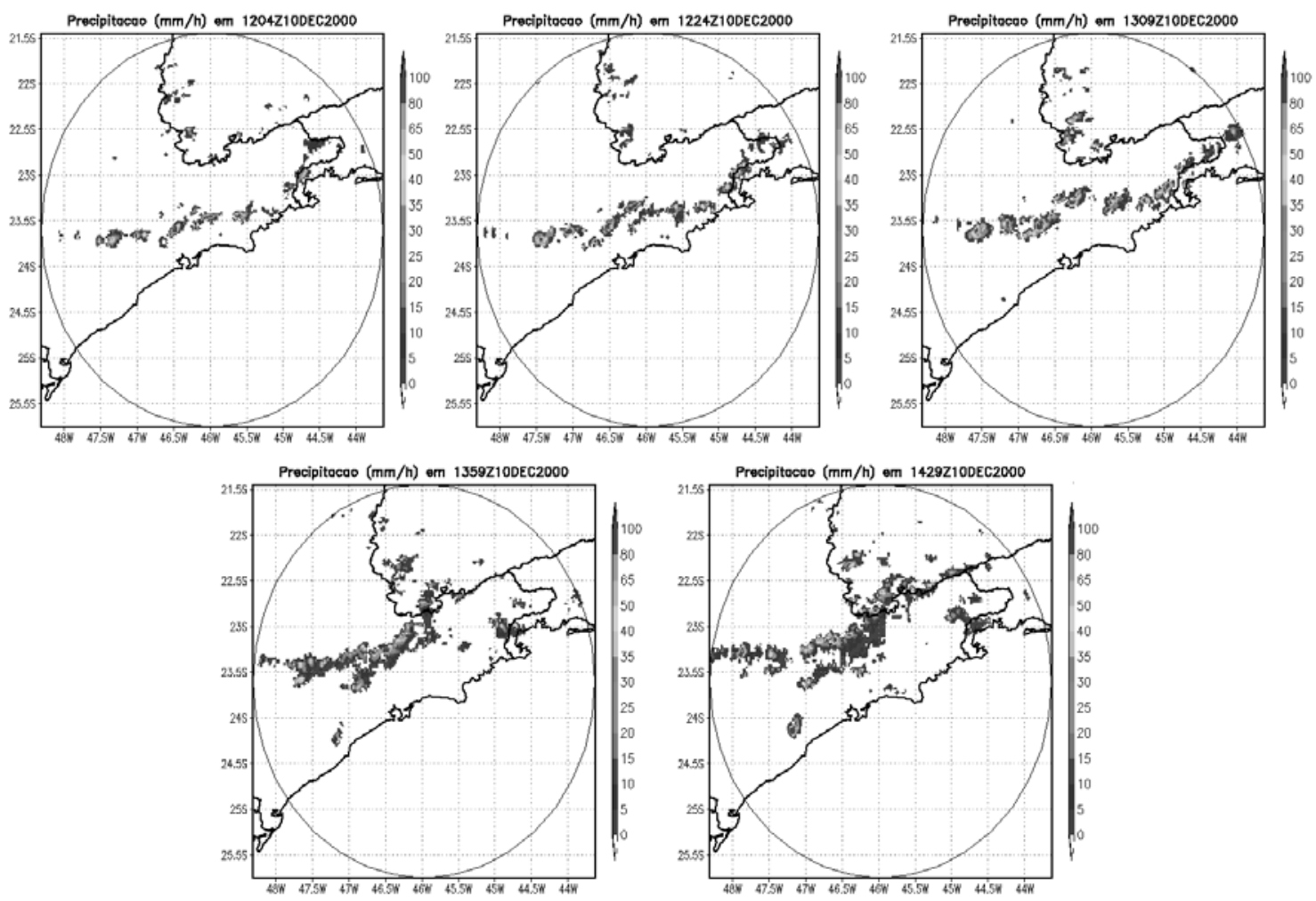

Figura 4 - Análogo à Figura 3, exceto para núcleos de convecção associadas a BM. 

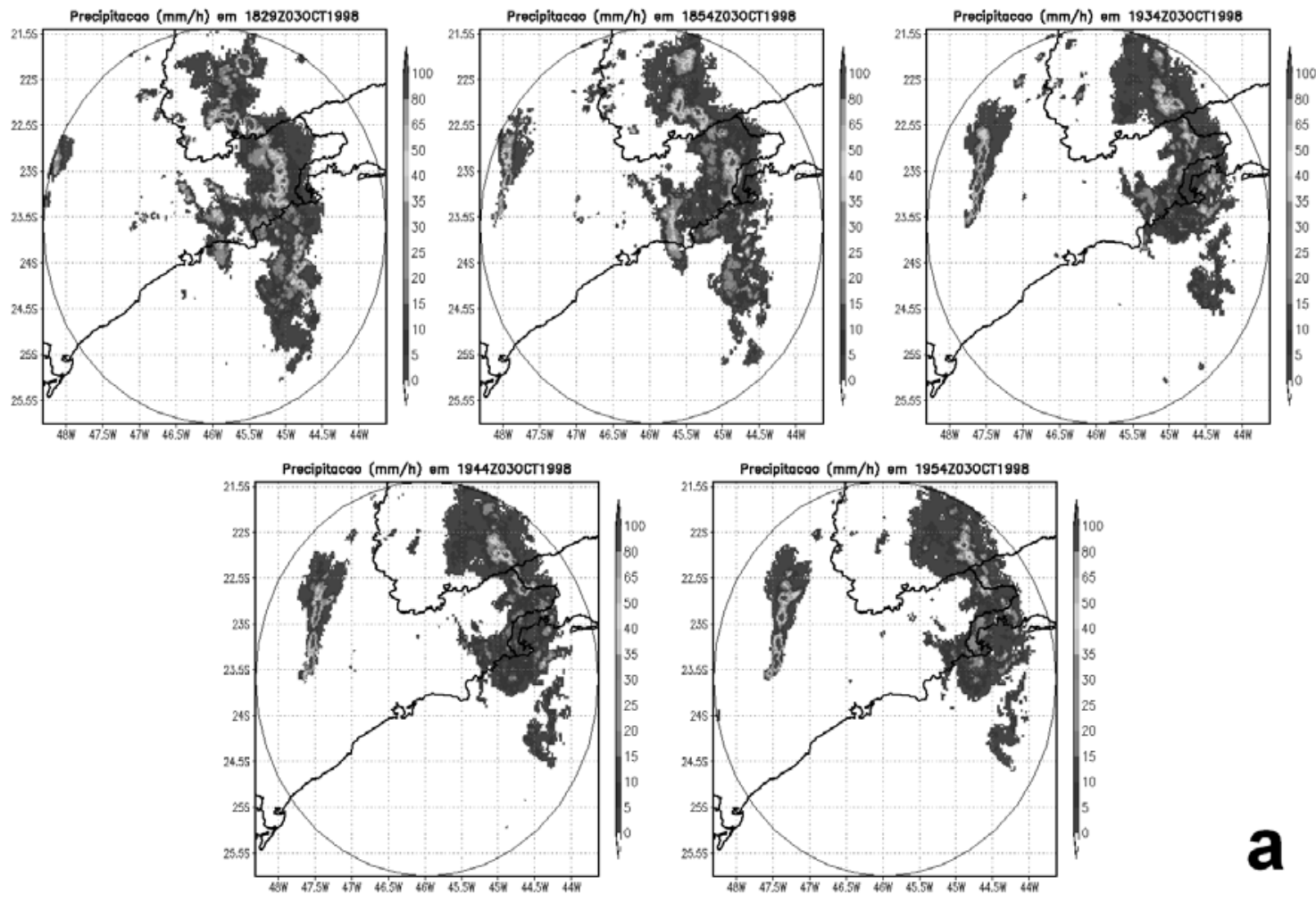

a
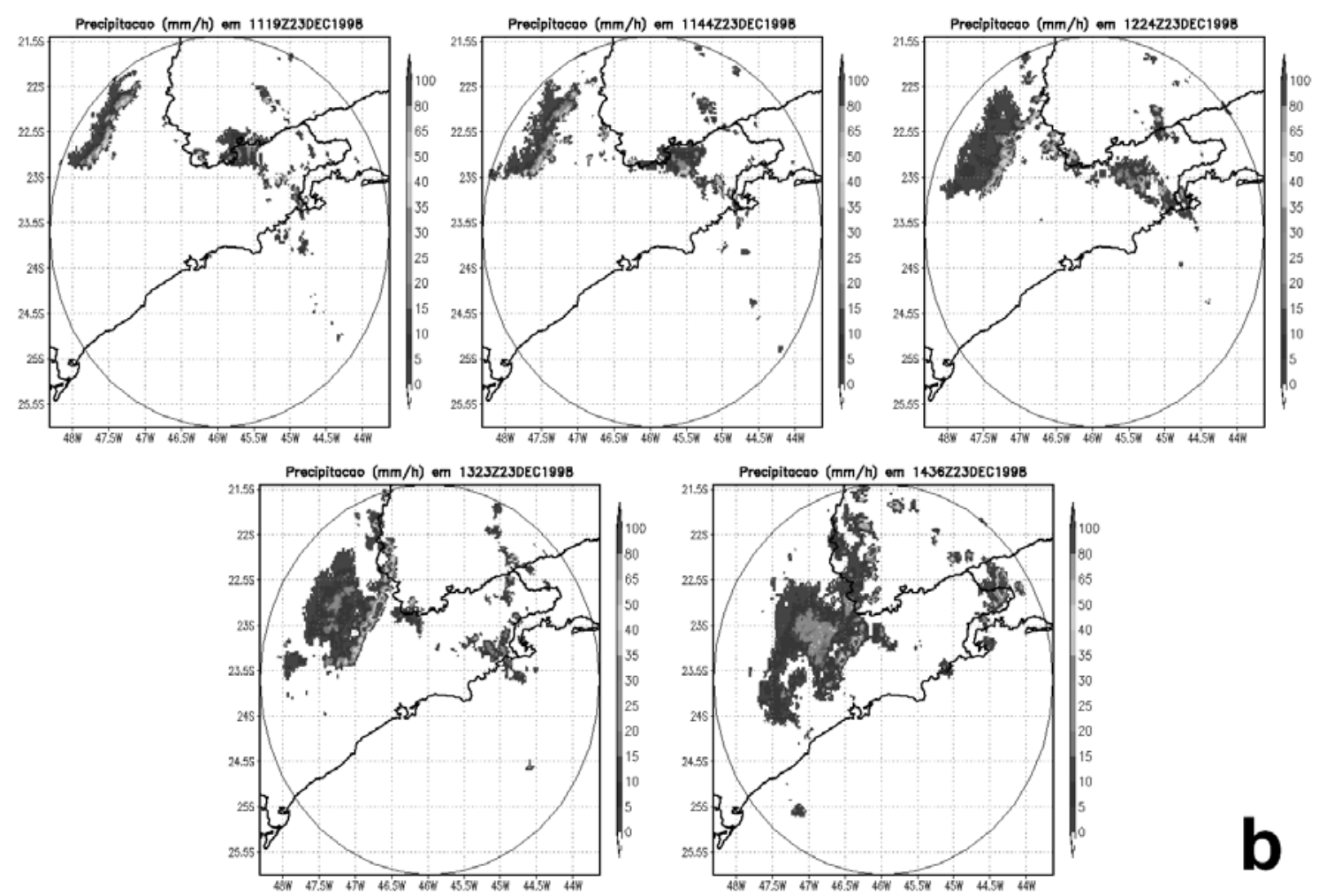

b

Figura 5 - Análogo à Figura 3, exceto para (a) LI na retaguarda de um sistema frontal e, (b) LI isolada. 
estacionárias e recebem aporte de umidade oriundo da Região Amazônica que evoluem para ZCAS e, desta forma, produzem bandas de precipitação intensas.

A morfologia e o tempo de evolução de cada categoria aqui observada dependem da topografia, circulação associada e processos de mistura induzidos pelo aquecimento diurno. O tamanho horizontal dos sistemas precipitantes se mostrou bastante variável. Núcleos convectivos associados a CI e a BM são os de menores dimensões, seguidos das LI, das FF e das BD de precipitação, nesta ordem. Estas análises foram feitas através de uma cautelosa observação dos campos de precipitação derivados de arquivos CAPPI do radar.

AFigura 8 mostra as freqüências dos $\mathrm{EC} \mathrm{e} \mathrm{EE,} \mathrm{dominantes}$ na primavera e verão e no outono e inverno, respectivamente. $\mathrm{O}$ relativo incremento de EE em Janeiro e Fevereiro (em relação a dezembro) está possivelmente associado a episódios de ZCAS. A freqüência de EC é máxima em Março (82.6\%), enquanto que para EE, é máxima em Julho (91.7\%).

A Figura 9 mostra as freqüências mensais para os diferentes tipos de sistemas. A CI é o sistema mais freqüente entre os meses de Novembro e Abril. A BM também tem sua maior freqüência neste período. As LI, com as características descritas em $2 \mathrm{a}$, têm menor freqüência relativa a outros sistemas na maior parte do ano, não tendo sido observadas nos meses de junho e julho. As FF são os sistemas dominantes de Maio a Outubro, embora também ocorram durante todo o ano. As BD ocorrem em todo o ano, com um pico de ocorrência nos meses de verão (provavelmente devido as ZCAS que ocorrem neste período) e nos meses de Agosto e Setembro, associadas à FF.

\section{b) Comparações entre as precipitações estimadas pelo RSP e medidas pela rede telemétrica da BAT}

As Figuras 10, 11, 12, 13, 14 e 15 apresentam os resultados das comparações para cada um dos tipos de sistemas de precipitação. Para cada evento de precipitação estimou-se o viés médio, em função da acumulação total média dos pluviômetros e dos pixels do radar correspondentes, e coeficientes de correlação para intervalos de acumulação de 10,30 , e 60 minutos.

Os resultados dos 92 dias estudados dos anos de 1999 e 2000 mostram que o radar, na maioria dos casos, tende a superestimar a precipitação, nos pontos relativos as medidas telemétricas. Em todos os casos, a mediana dos vieses radar/ pluviômetros apresentou valores próximos positivos, variando de 2,3 a 3,2. Analisando cada caso separadamente, observa-se
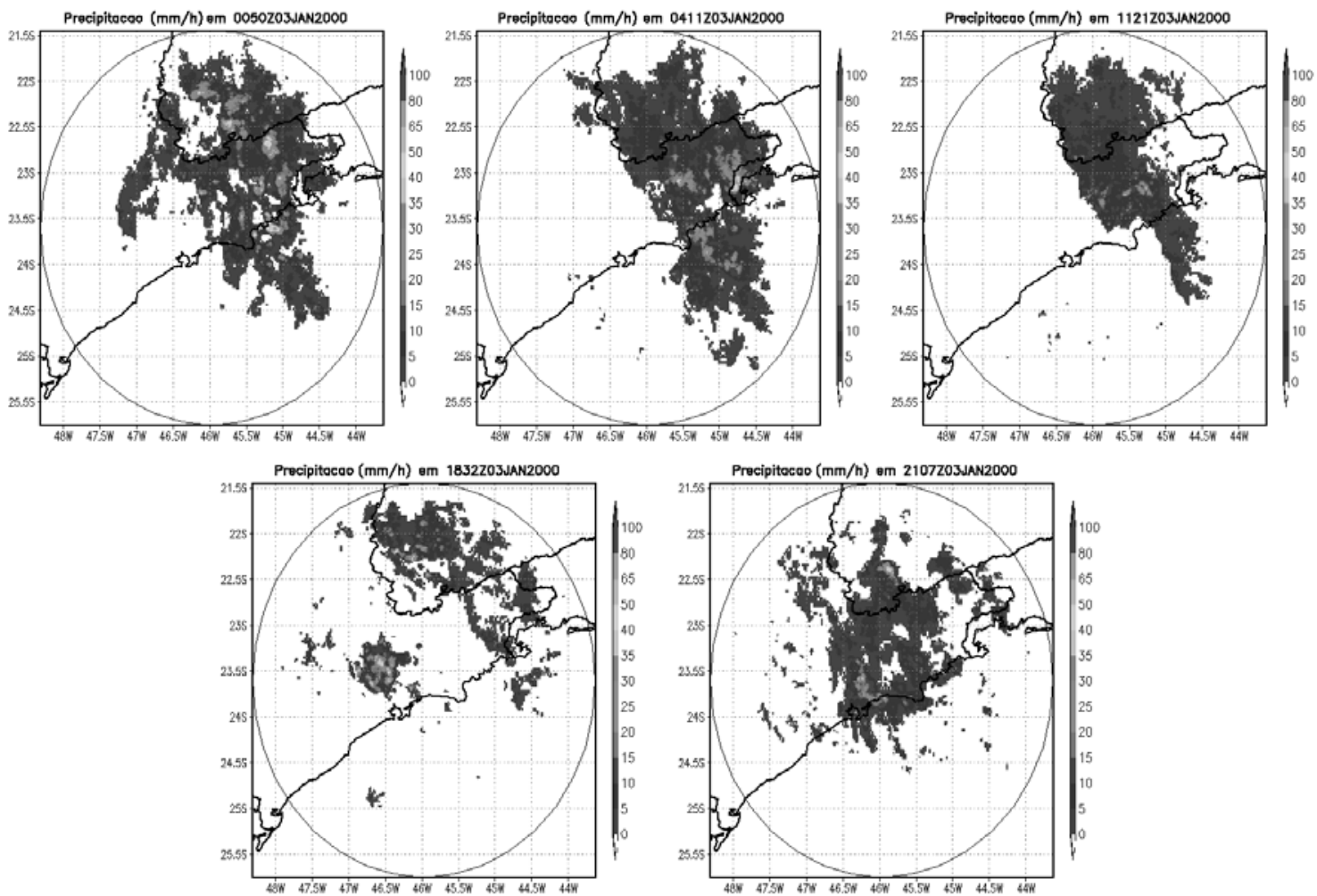

Figura 6 - Análogo à Figura 3, exceto para um episódio de ZCAS com BD com áreas convectivas e estratiformes. 

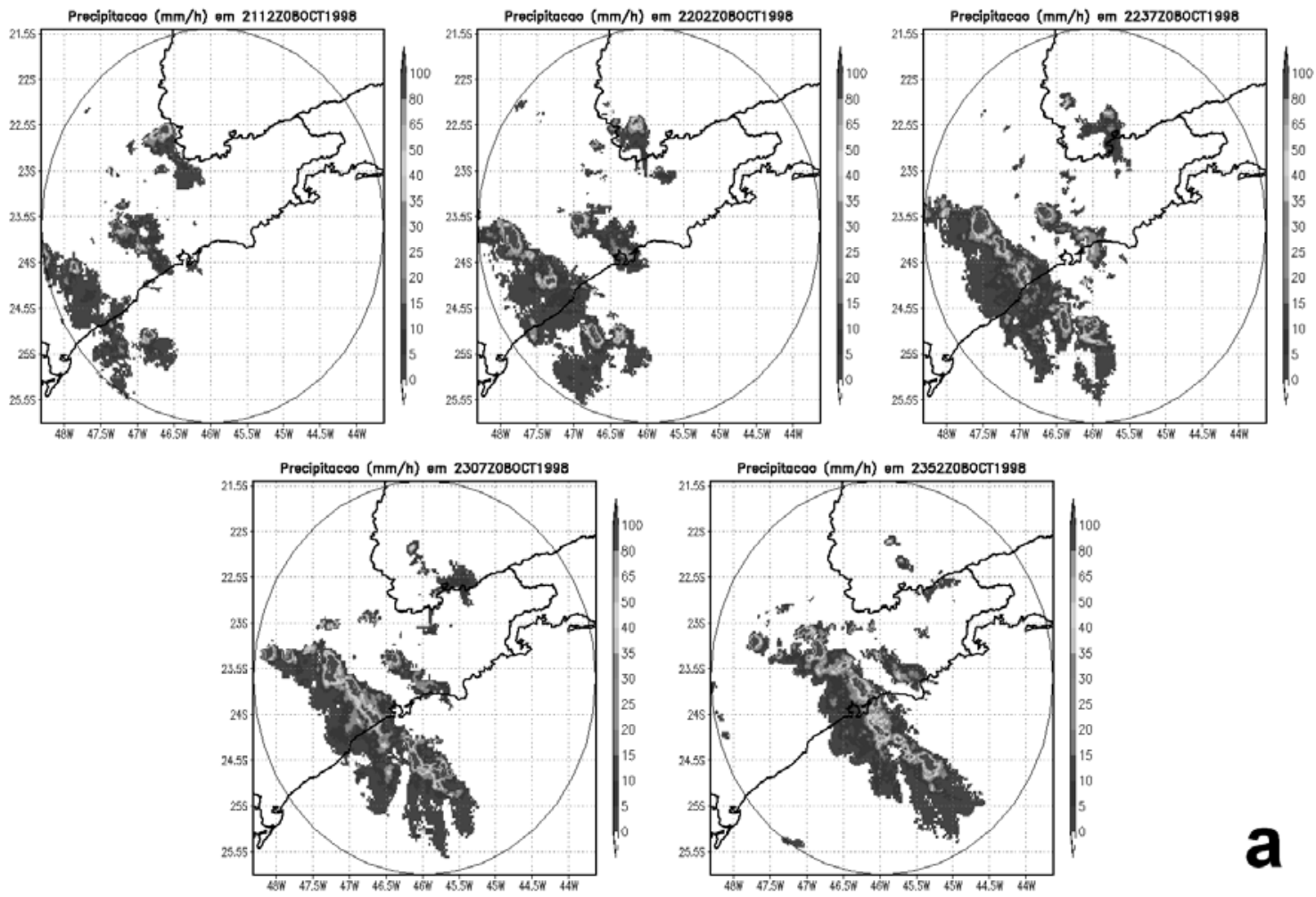

a
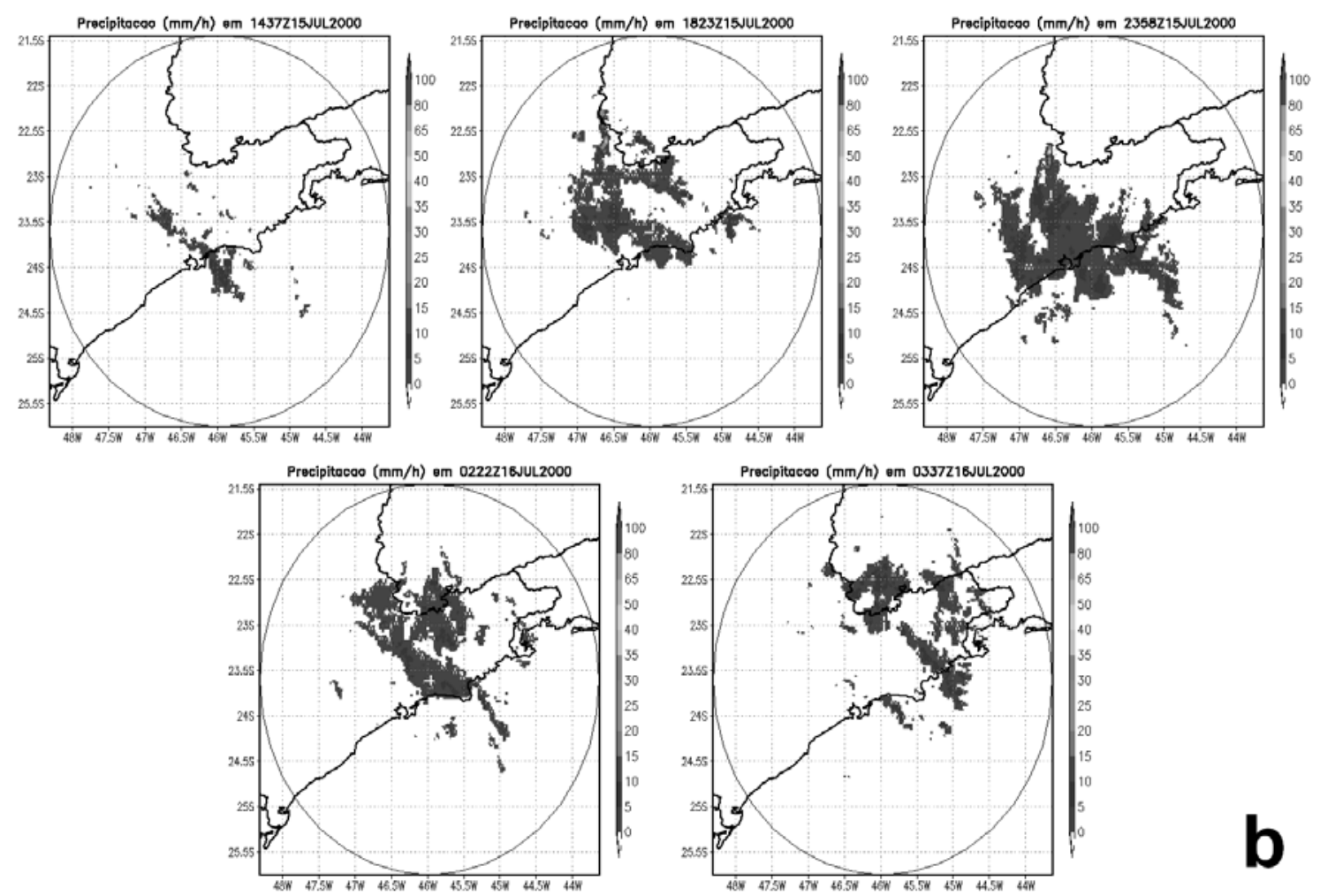

b

Figura 7 - Análogo à Figura 3, exceto para duas FF (a) com precipitação convectica e, (b), estratiforme. 


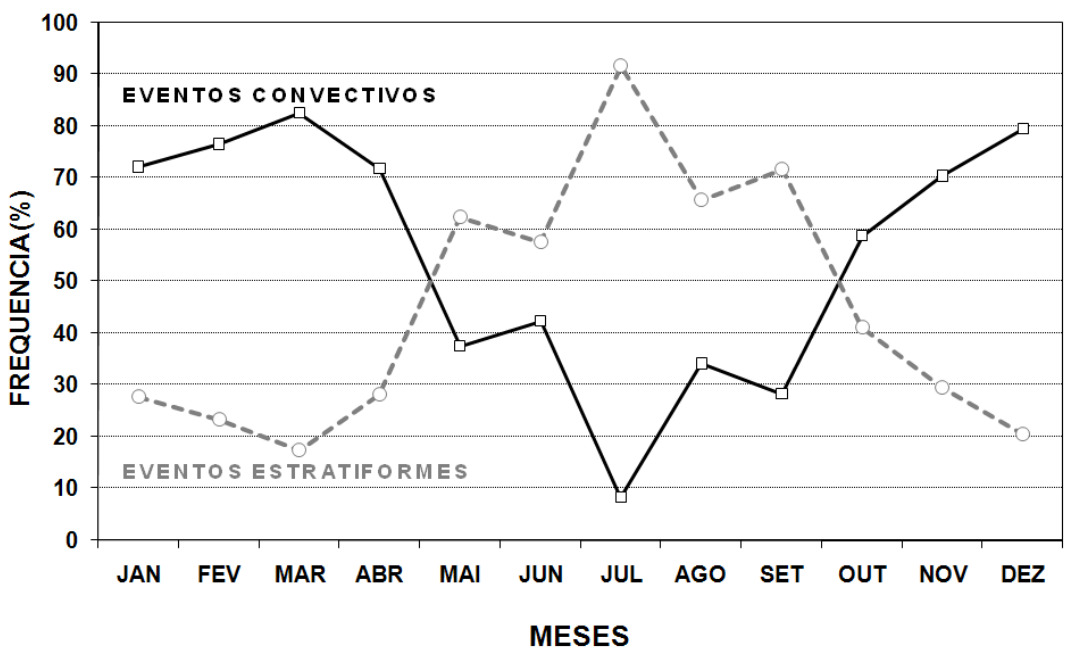

Figura 8 - Freqüências mensais de EC e EE.

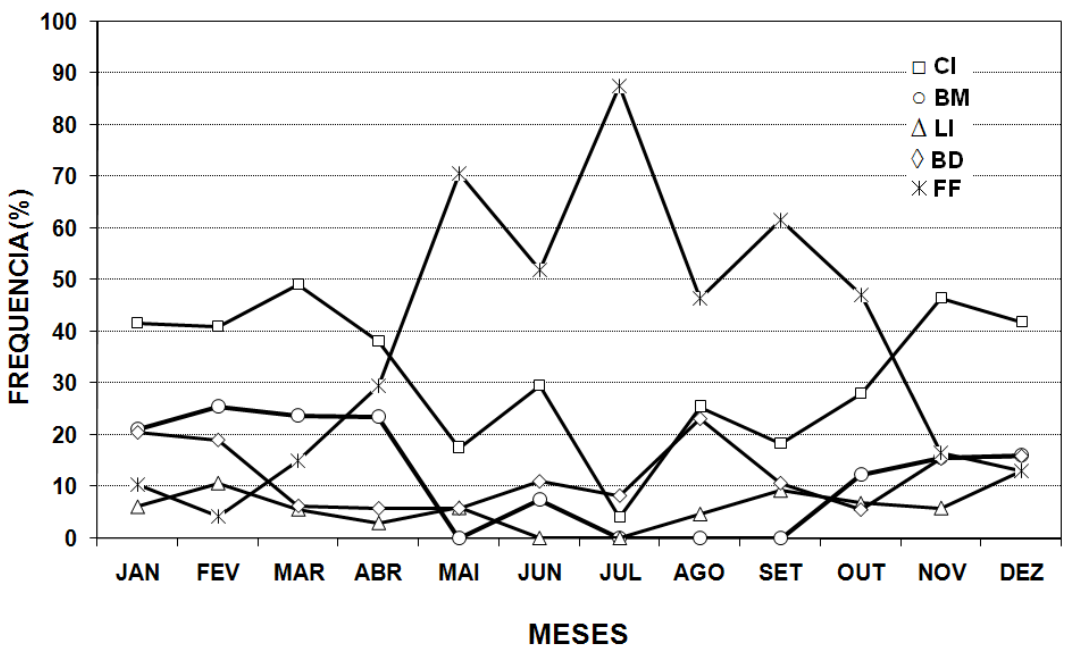

Figura 9 - Freqüências mensais dos diferentes tipos de sistemas de precipitação.

que, para os eventos de CI (Figura 10a), apesar dos valores dos percentis inferior $(25 \%)$ e superior $(75 \%)$ apresentarem valores próximos aos dos eventos de BM (Figura 10b) e das LI (Figura 10c), respectivamente, o comprimento da linha vertical entre valores mínimos e máximos observados é maior que os destes sistemas, o que está associado a eventos onde o radar superestimou a precipitação medida nos pluviômetros. Os vieses associados aos casos de BM estão na maior parte dos casos concentrados em torno do valor mediano (Figura 10B), e esta é a diferença principal deste sistema em relação aos casos de CI e de LI, com valores extremos de vieses positivos poucas vezes observados. O viés associado as LI tem padrão parecido aos casos de CI, exceto por apresentar menores extremos positivos de viés.

Devido às características dos vieses associados às BD e FF serem bem distintas dos três sistemas anteriores, cabe analisa-los separadamente. A suave diferença entre ambos mostra que os erros de estimativas entre radar e medidas pluviométricas associadas às $\mathrm{BD}$, apresentam um pouco mais de variabilidade, com vieses um pouco maiores nestes sistemas (Figura 10d). Os menores vieses associados às FF (Figura 10e) mostram a maior capacidade do radar em estimar com maior destreza a precipitação oriunda destes sistemas. A este fator deve-se associar a relação taxa de precipitação-refletividade utilizada, de Marshall e Palmer (1948), que apresenta melhores resultados em casos de precipitações homogêneas de eventos estratiformes em latitudes médias. Nestes casos, precipitações mais homogêneas e estratiformes são em muitos casos características de BD e FF.

Para a precipitação acumulada em 10, 30 e 60 minutos, foi observado que as correlações aumentam com o tempo de acumulação, o que sugere uma diminuição da variância temporal, 
para acumulações mais longas. Nos casos de CI (Figura 11) e BM (Figura 12), observa-se uma melhora nos valores de correlações para a acumulação de 30 minutos, não sendo muito acentuada a melhora destes valores para a acumulação de 60 minutos em relação à de 30 minutos, com razoável aumento da variabilidade entre os percentis inferior e superior. Este fator está associado à escala de tempo do sistema ao causar precipitação sobre um pluviômetro, muitas vezes de ordem inferior a 60 minutos, o que acaba por incrementar, também, mais erro associado a estimativa de chuva pelo radar. O valor mediano, nestes casos, aumenta suavemente para os maiores intervalos de acumulação. Para eventos de LI (Figura 13), nota-se um aumento nos valores das medianas, percentis e valores máximos e mínimos para o aumento gradual dos intervalos de acumulação. Estes sistemas, que geralmente causam precipitação convectiva de forte intensidade para intervalos geralmente curtos, muitas vezes ainda geram precipitações estratiformes de intensidades fracas a moderadas para intervalos de tempo da ordem ou maiores que 60 minutos.

Assim como na análise do viés, observa-se que os sistemas que apresentam as maiores correlações desde o intervalo de 10 minutos de acumulação, são as BD (Figura 14) e FF (Figura 15), com estas últimas apresentando os melhores resultados para o aumento gradual dos intervalos de acumulação. A diferença básica entre estes dois sistemas é o afastamento entre o valor mediano do percentil inferior nos três intervalos de acumulação, o que mostra que são poucos os eventos de BD onde as estimativas do radar se distanciam muito das medidas pluviométricas. As FF, por causarem geralmente precipitação por um tempo mais longo, e de forma mais homogênea sobre a rede telemétrica, apresenta um aumento gradativo dos valores da mediana, dos percentis e dos valores máximos e mínimos para as correlações encontradas.

\section{c) Correlações espaciais derivadas diretamente da precipitação estimada com o RSP}

Cerca de $30 \%$ do total de dias com CAPPI's disponíveis em que ocorreram sistemas de CI, BM, LI, B e FF, foram usadas para obter as correlações espaciais. Os coeficientes de correlação espaciais (Equação 1) foram calculados para quatro intervalos de acumulação. $\mathrm{O}$ ajuste das curvas do componente isotrópico das funções de correlações espaciais médias de todos os eventos de precipitação de cada sistema foi efetuado através das funções
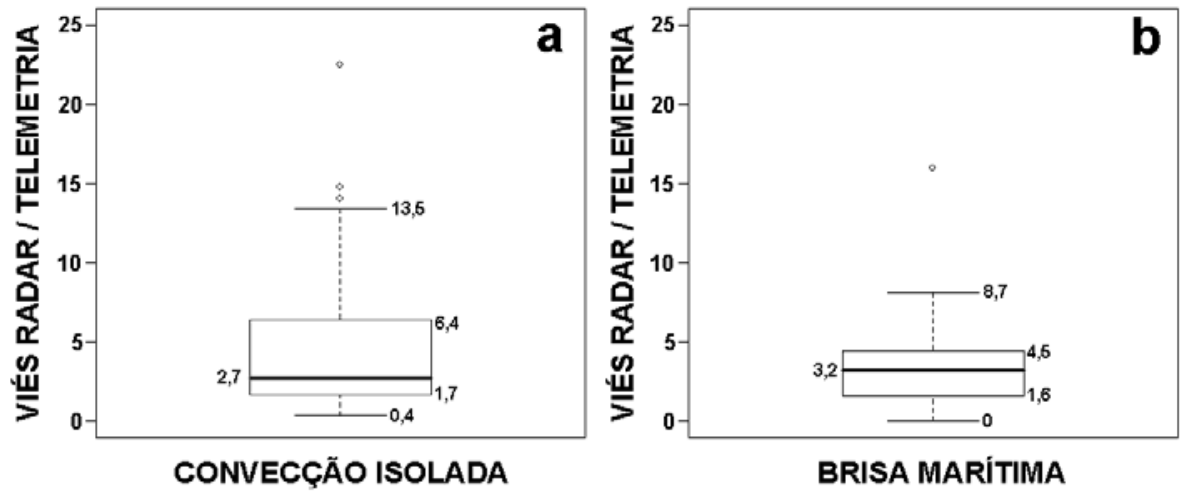

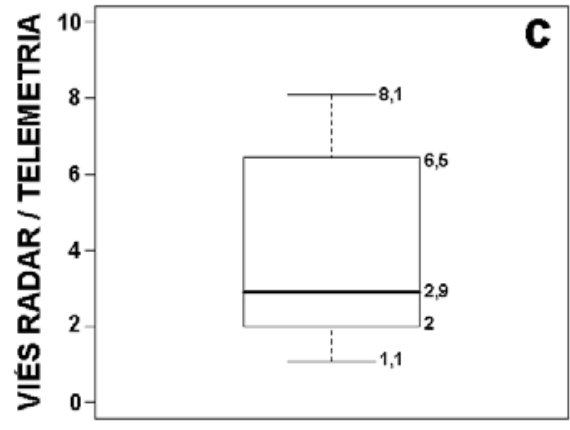

LINHAS DE INSTABILIDADE

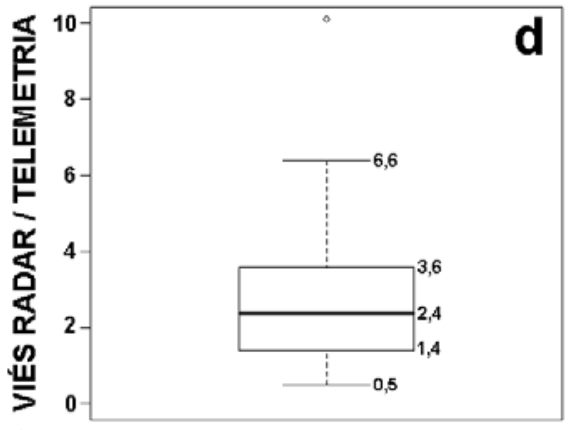

BANDAS DISPERSAS

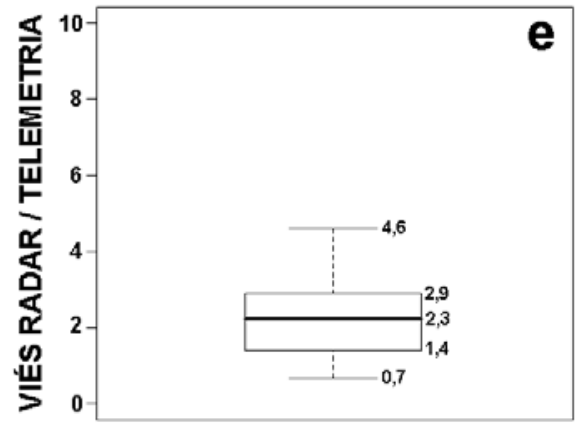

FRENTES FRIAS

Figura 10 - Plotagens box e whisker para o viés associado a eventos de CI (a), BM (b), LI (c), BD (d) e FF (e). As caixas denotam a mediana de $50 \%$ dos valores entre os percentis de 25 e $75 \%$, com a linha vertical compreendida entre os valores máximos e mínimos. A escala vertical para o viés varia de 0 a 25 para os casos a e b, e de 0 a 10 para os casos c, d, e. 

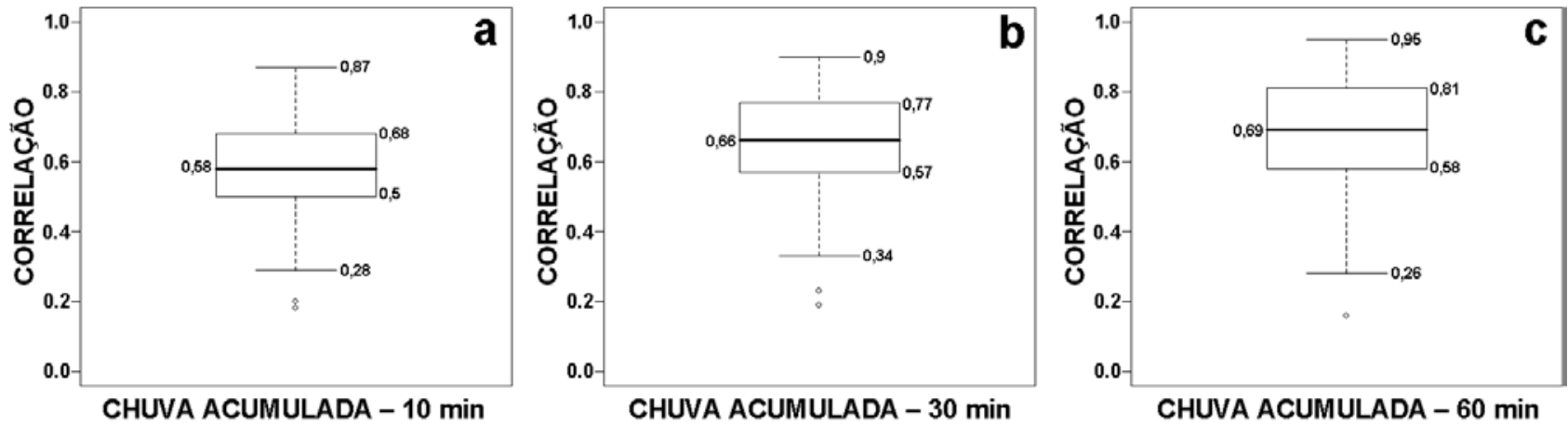

Figura 11 - Plotagens box e whisker para a correlação para intervalos de acumulação da precipitação de 10 minutos (a), 30 minutos (b) e 60 minutos (c), associado a eventos de CI. As caixas denotam a mediana de $50 \%$ dos valores entre os percentis de 25 e $75 \%$, com a linha vertical compreendida entre os valores máximos e mínimos.
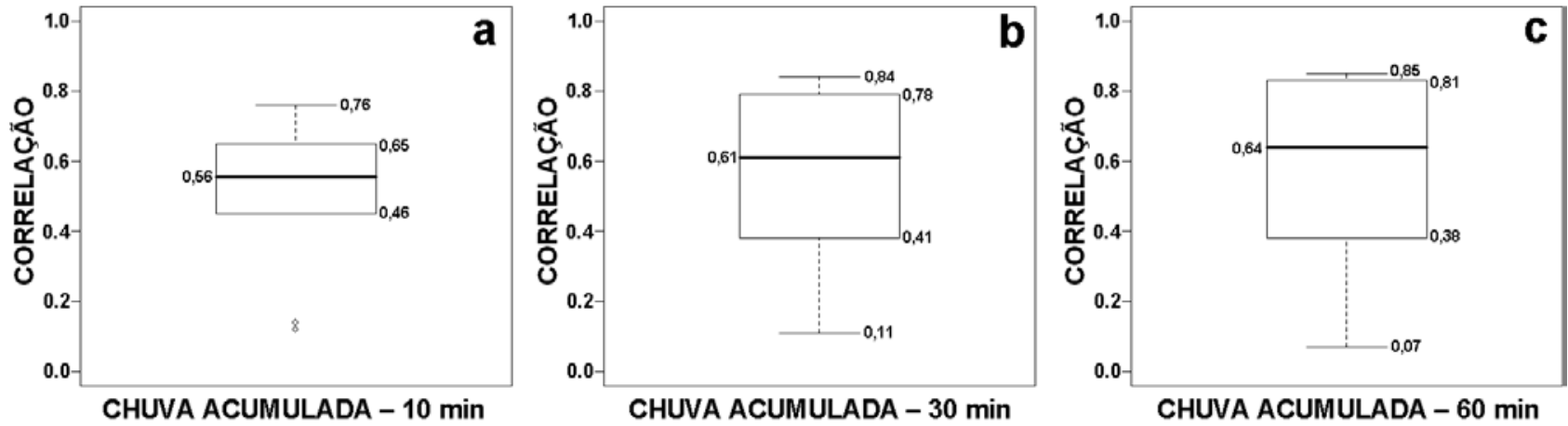

Figura 12 - Análogo a Figura 11, exceto para eventos de BM.
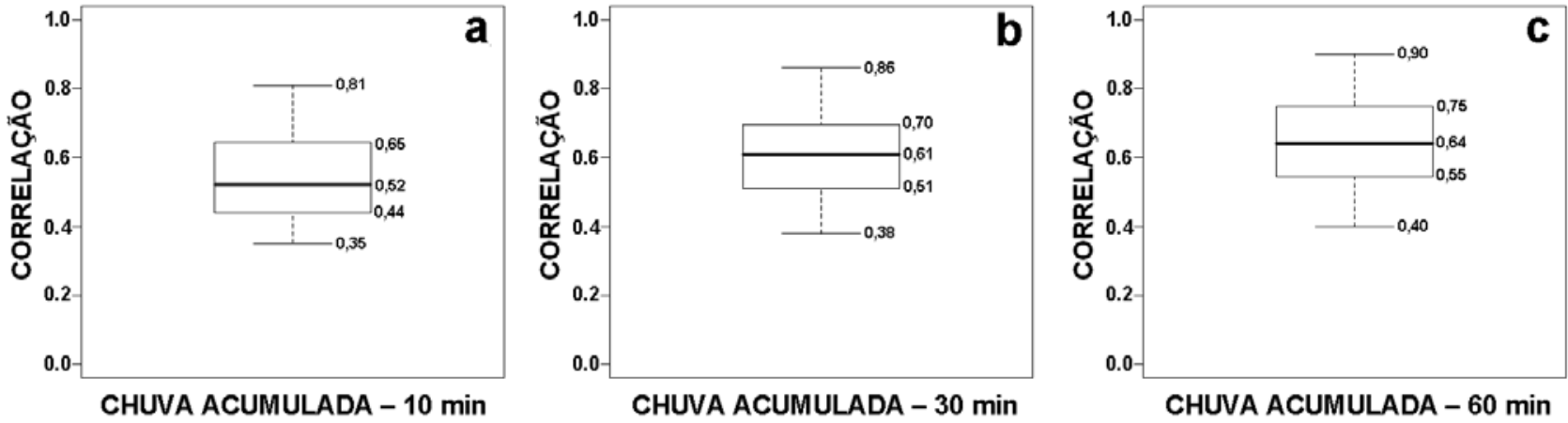

Figura 13 -Análogo a Figura 11, exceto para eventos de LI.
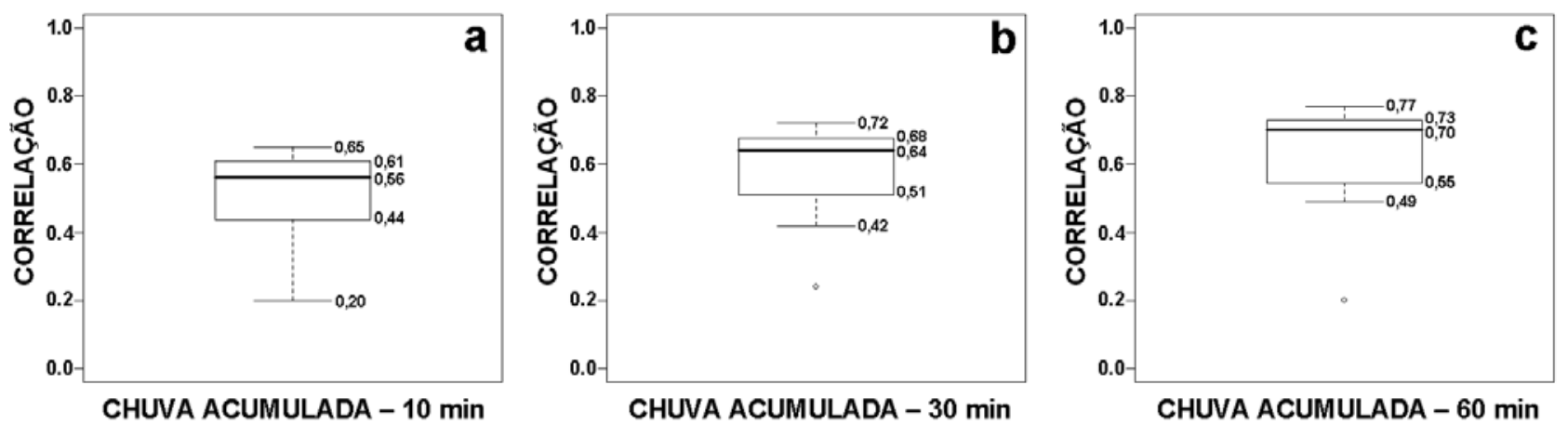

Figura 14 -Análogo a Figura 11, exceto para eventos de LI. 


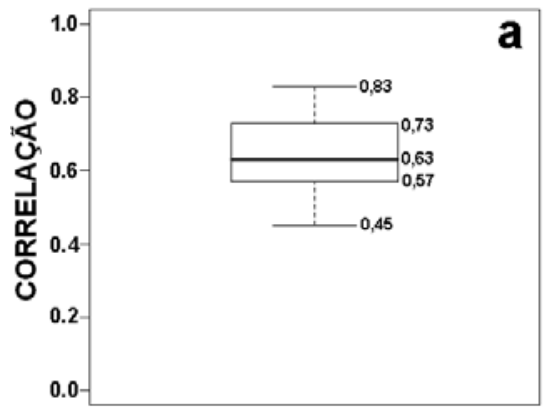

CHUVA ACUMULADA - $10 \mathrm{~min}$

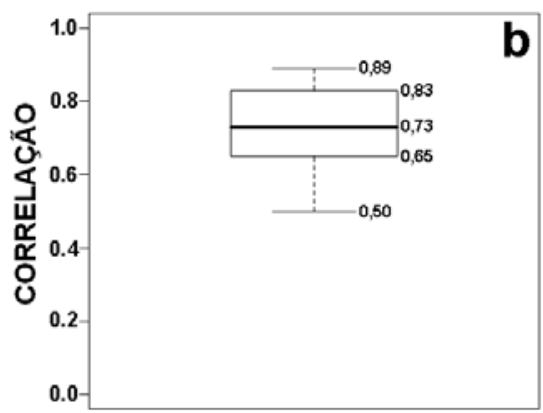

CHUVA ACUMULADA - $30 \mathrm{~min}$

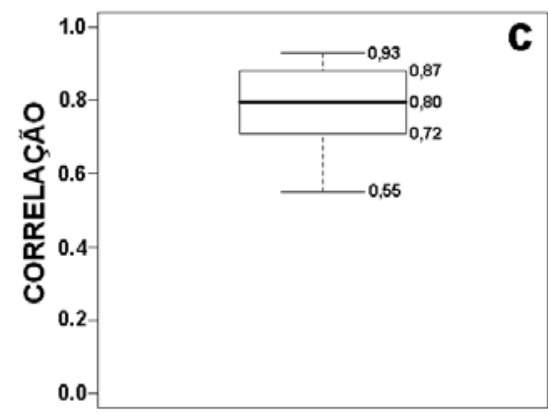

CHUVA ACUMULADA - $60 \mathrm{~min}$

Figura 15 - Análogo a Figura 11, exceto para eventos de FF.

polinomiais de sexta ordem. As curvas da Figura 16 mostram as correlações médias ajustadas em função da distância, e decrescem monotonicamente.

Os eventos de CI (Figura 16a) são caracterizados pela sua curta vida, a função de correlação espacial diminui rapidamente com a distância nos intervalos de acumulação descritos acima. A correlação espacial diminui para $0,5 \mathrm{em} 2,5 \mathrm{~km}$ para 15 minutos de acumulação, $5 \mathrm{~km}$ para 30 minutos de acumulação, 7,5 km para 60 minutos de acumulação e $10 \mathrm{~km}$ para 120 minutos de acumulação. Os valores de correlação chegam à zero em 10, 15,25 e $45 \mathrm{~km}$ para 15, 30, 60 e 120 minutos, respectivamente. Desta forma, esses sistemas mantêm uma coerência espacial muito limitada por cobrirem áreas relativamente pequenas. Igualmente, a propagação destes sistemas é limitada. Ao se acumular a precipitação para intervalos mais longos de tempo, esta pode ser devido a mais de uma célula convectiva, talvez forçada e advectada neste intervalo de tempo, com a precipitação estratiforme em seu estágio final de vida.

Para eventos de BM (Figura 16b), a correlação diminui para $0,5 \mathrm{em} 2,5 \mathrm{~km}$ e $5 \mathrm{~km}$ em 15 e 30 minutos de acumulação. Para 60 e 120 minutos de acumulação, a correlação decresce para 0,5 em 6 e $8,5 \mathrm{~km}$, respectivamente. Em comparação à CI, percebe-se que a precipitação associada à brisa marítima mantém correlação espacial por um intervalo de tempo ainda menor. Isto ocorre, porque a precipitação associada à brisa é de curta duração, muitas vezes na forma de células convectivas alinhadas devido a efeitos orográficos, com propagação mais rápida. As correlações caem para zero para distâncias de 8,5, 10,20 e $40 \mathrm{~km}$ para 15, 30, 60 e 120 minutos de acumulação, respectivamente.

As curvas de correlação espacial das LI (Figura 16c) apresentam características semelhantes a CI e a BM para os intervalos de acumulação de 15 e 30 minutos. A correlação diminui para 0,5 em 2 e $4 \mathrm{~km}$, respectivamente, devido ao deslocamento limitado pelo tempo de acumulação. Este tipo de sistema se desloca mais rapidamente do que os demais sistemas analisados. As áreas de maior acumulação são aquelas associadas com as células convectivas na dianteira da LI. Desta forma, tem características similares aos casos de CI e BM. Assim, para os intervalos de 60 e 120 minutos, a correlação diminui para 0,5 em 50 e $100 \mathrm{~km}$, respectivamente. A contribuição da região estratiforme para estes intervalos de acumulação é mais significativa e mais abrangente em área. Dentre os eventos convectivos (CI, BM e LI), as Linhas de instabilidade apresentam a maior coerência espacial para intervalos de acumulação mais longos.

FF e BD são semelhantes para os intervalos de acumulação de 15 e 30 minutos (Figuras 16d e 16e). A correlação espacial diminui para $0,5 \mathrm{em} 20 \mathrm{~km}$ em 15 minutos, e $35 \mathrm{~km}$ e $45 \mathrm{~km}$ para 30 minutos de acumulação, aproximadamente. Para os intervalos de acumulação de 60 e 120 minutos, há diferenças da ordem de $10 \mathrm{~km}$, a correlação cai a $0,5 \mathrm{em} 20$ e $30 \mathrm{~km}$, respectivamente. A correlação é nula em 65 e $100 \mathrm{~km}$ no caso das FF e 120 e $150 \mathrm{~km}$ no caso das bandas dispersas. As BD são sistemas precipitantes ainda mais uniformes do que as $\mathrm{FF}$, com áreas de precipitação mais extensas e de mais longa duração.

Estes resultados indicam que a estimativa da chuva tende a melhorar para intervalos crescentes de acumulação, em parte por se tratar de um processo integrador com filtragem do tipo passa-baixa.

\section{CONCLUSÕES}

Sistemas como CI e BM se formam preferencialmente no período da tarde, entre os horários das 13:30 HL e 18:30 HL e 14:30 HL e 19:00 HL, respectivamente. São sistemas semelhantes caracterizados geralmente por núcleos intensos de precipitação convectiva. A principal diferença entre os sistemas está no sentido de deslocamento e na organização. As LI atuam associadas ou não a sistemas de maior escala, como frentes frias. Elas atuam em todos os horários com predominância no período entre as 15:00 HL e as 17:00 HL. Isto ressalta também, o papel do ciclo do aquecimento diurno na formação destes sistemas, assim como da CI e da BM. 
BD ocorrem com maior intensidade, geralmente no período de ZCAS, com áreas de precipitação convectiva embebidas em áreas de precipitação estratiforme. São sistemas que persistem por um período de até 5 dias. A precipitação associada a este tipo de sistema é contínua na maior parte do dia. Apresentam como característica mais marcante, o sentido de deslocamento da precipitação que é de noroeste para sudeste.

a

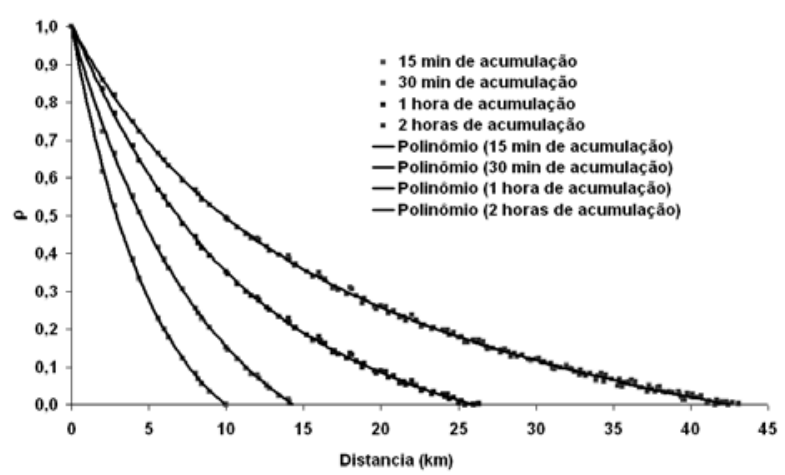

C

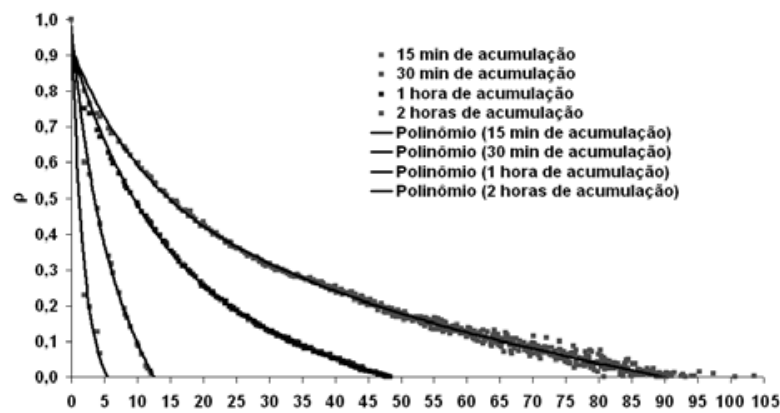

Distancia (km)
As FF, assim como as BD, atuam, algumas vezes, por até mais de 5 dias. Por muitas vezes se deslocam pela área de cobertura do radar em poucas horas. Em média, seu período de atuação foi de 18 horas. Apresentam também como característica principal, o seu sentido de deslocamento, de sudoeste para nordeste.

A comparação entre a precipitação medida pela rede telemétrica e a estimada pelo radar revelou que, na grande b

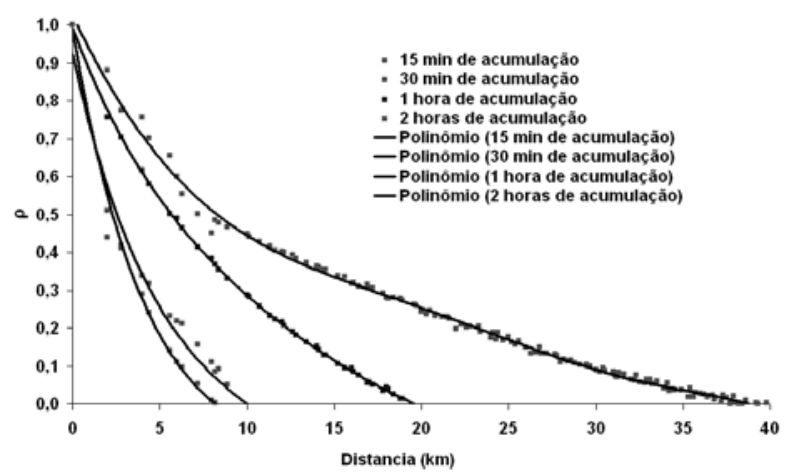

d

Correlaçöes Espaciais - Bandas Dispersas

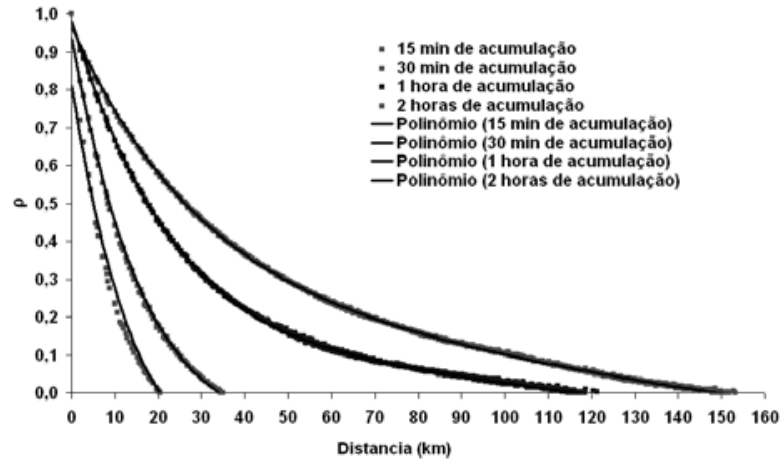

C Correlaçōes Espaciais - Frentes Frias

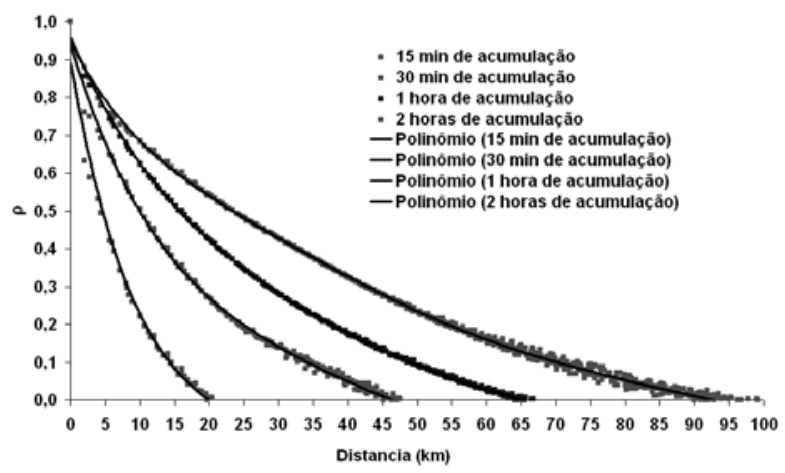

Figura 16 - Coeficientes de correlações espaciais médias estimados de acumulações de precipitação com o radar meteorológico de São Paulo para píxeis de $2 \mathrm{~km} \times 2 \mathrm{~km}$, para casos de CI (a), BM (b), LI (c), BD (d) e FF (e). Os intervalos de tempo das acumulações são indicados, assim como a curva polinomial que melhor ajusta os dados. 
maioria dos casos, o radar superestima a precipitação medida pela telemetria. $O$ viés entre radar e telemetria (dado pela razão entre ambos) foi relativamente alto, variando entre 2,3 e 3,2, porém com grande variabilidade entre os sistemas. $\mathrm{O}$ resultado da análise das correlações, entre a precipitação observada versus a estimada pelo radar para os sistemas, mostrou que as correlações aumentam para intervalos maiores de acumulações da precipitação, com as frentes frias apresentando os melhores resultados. Pode-se atribuir muito deste resultado à relação Z-R que é empregada, pois é mais indicada onde existe a atuação predominante de sistemas que causam precipitações homogêneas e estratiformes, geralmente em latitudes médias, porém, as precipitações de verão são as que dominam a RMSP, com forte convecção associada.

Ao se analisar as correlações espaciais para os sistemas, diretamente dos campos de precipitação do radar, foram obtidas curvas de correlação para quatro intervalos de acumulação diferentes, 15, 30, 60 e 120 minutos. Os resultados indicam que sistemas de vida curta e com menor abrangência espacial (e.g., CI e BM) possuem correlações espaciais que decrescem rapidamente com a distância, atingindo poucos quilômetros mesmo para intervalos de acumulações maiores. Para as LI, estas correlações persistem até maiores distâncias no caso de intervalos de acumulação de 60 e 120 minutos. Os sistemas de vida mais longa e que abrangem áreas maiores (e.g., BD e FF), apresentaram maiores correlações com a distância do que para os demais sistemas, principalmente para os intervalos de acumulação de 60 e 120 minutos. Estes resultados corroboram os obtidos da comparação direta das estimativas do radar em relação às medidas pluviométricas.

A partir dos resultados aqui discutidos, pode-se partir para métodos de classificação dos sistemas com uso de algoritmos que distingam sistemas convectivos dos estratiformes, assim como detalhar com mais acerácea características dos sistemas como a velocidade de deslocamento, uma vez que neste estudo estas características foram obtidas de maneira mais subjetiva, analisando uma grande quantidade de campos de taxas de precipitação. Uma vez obtidas as correlações espaciais para os sistemas, é possível a aplicação de uma técnica de análise objetiva estatística (ANOBES), para a integração de estimativas de radar a medidas telemétricas, para geração de novos campos de precipitação mais realistas do que os obtidos puramente de qualquer um destes dois sistemas de medição.

\section{REFERÊNCIAS BIBLIOGRÁFICAS}

AUSTIN, P. M., Relation between measured radar reflectivity and surface rainfall. Monthly Weather Review, 115, p.10531070, 1987.

BARROS, M.T.L.; BRAGA JR B.P.F. São Paulo Flood Warning
System : Integrating Different Levels of Data Quality and Availability. In: 2nd. International. Symposium on Hydrological, Applications of Weather Radar, Hannover, Alemanha, 1992.

BLANCO, C. M. R.; MASSAMBANI, O. Orographic Enhancement in São Paulo, Brazil: a Preliminary Case Study. In: 28th Conference on Radar Meteorology, Austin, Texas, 1997.

CHANDRASEKAR, V.; ZAFAR, B. Precipitation Type Determination From Spaceborne Radar observations. IEEE Transactions on Geoscience and Remote Sensing, 42(10), p.2248-2253, 2004.

CHOW, V. T.; MAIDMENT, D.; MAYS, L. Apllied Hidrology, McGraw Hill, New York, 1988.

CLIMANÁLISE: Boletim de monitoramento e análise climática. Cachoeira Paulista: CPTEC-INPE, Mensal. ISSN: 0103-0019 CDU-555.5, 2000. Disponível em: <www.cptec. inpe.br/revclima/boletim/>.

CREUTIN, J. D.; OBLED, C. Objective analysis and mapping techniques for rainfall fields: An objective comparison. Water Resources and Research., 18, p.413-431,1982.

EVANS, J. S.; DOSWELL, C. A. Examination of Derecho Environments using proximity soundings. Weather and Forecasting, 16: p.329-342, 2001.

GAN, M. A., RAO, V. B. Surface Cyclogenesis over South America. Monthly Weather Review, 119, p.1293-1302, 1991.

LEGATES, D. R.; McCABE, G. J. Evaluating the Use of "Goodness of Fit" measures in Hydrologic and Hydroclimatic Model Validation. Water Resources Research, 35, p.233-241, 1999.

MARSHALL, J. S.; PALMER, W. M. K. The distribution of raindrops with size. Journal of Applied Meteorology, Boston, v. 5, p.165-166, 1948.

MARENGO, J. A.; TOMASELlA, J.; UVO, C. R. Trends in streamflow and rainfall in tropical South America : Amazonia, eastern Brazil, and northwestern Peru. Journal of Geophysical Research, 103: (D2), p.1775-1783, 1998.

PEREIRA FILHO, A. J. Radar measurements of tropical summer convection: urban feedback on flash floods. In: 29th International Conference on Radar Meteorology, Montreal, Quebec. Boston, Massachusetts : American Meteorological Society, p.939-940, 1999.

PEREIRA FILHO, A. J.; CRAWFORD, K. C. Integrating WSR-88D estimates and Oklahoma Mesonet Measurements of rainfall accumulations: a statistical approach. In: 27th International Conference on Radar Meteorology, Vail, Colorado. Boston, Massachusetts. American Meteorological Society, p.240-242, 1995.

PEREIRA FILHO, A. J. ; CRAWFORD, K. C. ; HARTZELL, 
C. . Improving WSR-88D hourly rainfall estimates. Weather and Forecasting, v. 13, n. 4, p.1016-1028, 1998.

PEREIRA FILHO, A. J.; NAKAYAMA, P. T. Intercomparison of radar Rainfall. Estimates and Rain Gauge Measurements in São Paulo, Brazil. 5th International Symposium on Hydrological Applications of Weather Radar, Kyoto, Japan, 2001.

PEREIRA FILHO, A. J.; SILVA, F D S. The morphology of tropical rainfall systems and their hydrological significance. In: 32nd conference on radar meteorology, Albuquerque. Boston: American Meteorological Society, 2005.

PEREIRA FILHO, A. J.; M. T. L. BARROS.; BRAGA JR, B. P. F. Precisão das medidas de precipitação do radar meteorológico de São Paulo. VI Congresso Brasileiro de Meteorologia,

Salvador, BA, Vol. II, p.790-797, 1990.

PEREIRA FILHO, A. J.; BARROS, M. T. L. Flood warning system for megacities: a Brazilian perspective. In: International Conference on Hydrology in a changing environment, British Hydrological Society, 1998.

PISANI, A. Avaliação dos Dados do Radar Meteorológico de São Paulo para Aplicação em Hidrologia, Tese de Doutorado,
Dep. de Engenharia Hidráulica /Escola Politécnica da Universidade de São Paulo, 1995.

ROCHA, A. M. G. C.; GANDU, A. W. A Zona de Convergência do Atlântico Sul. Climanálise, São José dos Campos (SP), v. Esp., p. 140-142, 1996.

SATYAMURTY, P.; FERREIRA, C. C.; GAN, M. A.. Cyclonic vortices over South America, Tellus, v. 42A, p. 194-201, 1990.

SILVA DIAS, M. A. F., Storms in Brazil, in Hazards and Disasters Series, Storms Volume II, edited by R. Pielke Sr. and R. Pielke Jr., p. 207-219, Routledge, New York, 1999.

SMITH, J. A.; SEO, D. J.; BAECK, M. L.; HUDLOW, M. D. An intercomparison study of NEXRAD precipitation estimates. Water Resource Research, 32, p.2035-2045, 1996.

STELLMAN, K. M.; FUELBERG, H. E. An Examination of Radar and Rain Gauge-Derived Mean Areal Precipitation over Georgia Watersheds. Weather and Forecasting, 16, p.133-144, 2001.

WILKS, D. D. Statistical Methods in the Atmospheric Sciences. 2a Edição, 627 p, 2006.

ZAWADZKI, I. I. Statistical properties of precipitation patterns. Journal of Applied Meteorology, 12, p.459-472, 1973. 